\title{
Perceived stress and its associated factors among health care providers during COVID-19 outbreak in Ilu Aba Bor and Bunno Bedelle Zones of Oromia regional state, South West, Ethiopia, 2020:A Cross sectional study
}

Yadeta Alemayehu ( $\square$ yadoalex45@gmail.com )

Mettu University

Adamu kenea

Mettu University

Ebsa Gelan

Mettu University

Geremew Tolesa

Mettu University

Lemi Bacha

Mettu University

\section{Research Article}

Keywords: stress, health care providers, COVID-19, South West Ethiopia

Posted Date: March 9th, 2021

DOI: https://doi.org/10.21203/rs.3.rs-296267/v2

License: (c) (1) This work is licensed under a Creative Commons Attribution 4.0 International License. Read Full License 


\section{Abstract}

Background: Pandemic corona virus outbreak has global distribution and world health organization stated that there is a high risk of pandemic corona virus out spreading to other developing countries that can make health professionals serving in third world countries to fear for morbidity and mortality.

Objectives: To assess level of perceived stress and associated factors among health care providers during corona virus outbreak in Ilu Aba Bora and Bunno Bedelle Zones, Oromia regional state South West Ethiopia 2020.

Methods: Facility based cross sectional study design was conducted among 365 respondents. Perceived stress was assessed using perceived stress scale (PSS) instrument. The data was organized and processed by the use of epi info-7 and analyzed using SPSS version 21.

Results: The prevalence of perceived stress due to pandemic corona virus management among health care providers working in public health facilities was $57 \%$ in the last month of this study period. In Multivariate logistic regression being married ( $A O R=4.6,95 \% \mathrm{Cl}: 3.51 ; 9.33)$, less than one year working experience $(A O R=2.57,95 \% \mathrm{Cl}: 1.83-7.32)$ and having $\mathrm{BSc}$ degree and lower educational background in health related fields $(\mathrm{AOR}=3.8,95 \% \mathrm{Cl}: 3.81 ; 7.03)$ had significantly associated with perceived stress among health care providers at $p$ value of less than 0.05 .

Conclusion: Lower work experience, being married and lower educational background was significantly associated with perceived stress. Ministry of health in collaboration with ministry of education and other stakeholders should facilitate stress management skills inductive trainings to practitioners of newly recruited health care providers working in health care facilities.

\section{Introduction}

World health organization stated that there is a high risk of pandemic corona virus out spreading to other countries around the globe that can make third world countries to fear for morbidity and mortality $(1,2)$. Subjective well-being of health care providers due to corona virus included the way one's evaluation of his/ her life and consisted of two dimensions, cognitive and emotional. While it is critical during this time to take care of physical health and also need to pay attention to emotional health of the clients.

Emotional reactions that the clients may experience to corona virus include anxiety, worry, fear, sadness, tearfulness, and/or loss of interest in usual enjoyable activities(3).

Globally, living through the threat of the public health emergency including pandemic corona virus outbreak can be extremely stressful. The direct relationships of health care providers and patients with corona virus increase level of stress(4). Studies show that working in sever acute respiratory syndrome that affected patients in hospitals could have been traumatic among health care providers that threatens an individual's life or physical integrity and involves a subjective response of fear, helplessness, or 
horror(5). Acute stress may lead to enhanced or impaired immune function, while chronic stress clearly has an adverse impact on immune function thus it leads to greater susceptibility to infection(6).

Health care provider is a person who is responsible for the twenty four hour monitoring of patients with corona virus that continually exposed them to stressful factors. Researches indicating that health care professions are influenced by the negative impacts of physical and psychological stresses due to corona virus outbreak that caused by the occupational related activities(7). Strong feelings that won't go away, last longer than a few weeks of corona virus fearing, or interfering with normal functioning may lead them to be symptom of depression or anxiety(8). Behavioral reactions triggered by stressful events need to be stopped because they cannot only harm physical and mental health, but they also make the situation worse for others. Cognitive reactions to stress of COVID-19 can affect ability to think clearly, make it harder to pay attention, solve problems or remember that exacerbate common reactions in times of high stress $(9,10)$. This study assessed level of perceived stress and associated factors among health care providers during corona virus outbreak in Ilu Aba Bor and Bunno Bedelle Zones, Oromia regional state, South West Ethiopia.

\section{Methods}

\section{Study area and study period}

This facility based cross sectional study was conducted in selected health facilities of llu Aba Bor and Bunno Bedelle zones of Oromia Regional state, South West Ethiopia. llu Aba bora zone had one town administration and fourteen rural districts with estimated total population of 1,606,502. llu Aba Bor Zone has three hospitals, 40 health centers and 273 health posts to serve communities. Ilu Aba bora zone had also one referral, one fistula and one district hospitals that are serving population in the zone and surroundings. The only referral hospital in the zone is Mettu Karl Hospital that serves as a referral hospital in the zone and Gambela Regional State as well as adjacent districts of the SNNPR. Buno Bedelle Zone had four district hospitals, 31 health centers and 256 health posts to serve surrounding communities that estimated 821,000 of the population. Among the above health facilities four hospitals and six health centers was selected to address the objectives of the study. The study was conducted from March to August, 2020.

\section{Study design}

Facility based cross sectional study design was conducted to assess the level of perceived stress and its associated factors among health care providers during corona virus outbreak in llu Aba Bor and Bunno Bedelle Zones of Oromia regional state, South West, Ethiopia.

\section{Source and study population}




\section{Source population}

The source population was all health care professionals in llu Aba Bora and Buno Bedelle zones.

\section{Study population}

The study population was all health professionals in the selected health facilities in Ilu Aba Bora and Bunno Bedelle zones.

\section{Inclusion and exclusion criteria}

\section{Inclusion criteria}

Health care professionals whose were available in the selected health facilities during data collection period.

\section{Exclusion criteria}

Those who were on annual leave, sick leave and critically ill unable excluded from the study participation.

\section{Sample size determination and sampling procedures}

\section{Sample size determination}

The required sample size was calculated using a single proportion formula to obtain sample size needed to estimate the extent of perceived stress level among health care workers. The prevalence of perceived stress level was unknown. Therefore proportion 50\%, confidence interval $=95 \%$ and margin of error $(d)=$ $5 \%$ was taken. Hence, the required sample size was 384 . Since the source population is less than 10,000 and a sample size of 365 was used with $5 \%$ non-response rate. The sample was obtained with the proportion allocation system among each health centers and hospitals based on the ratio of total number of professional health care workers in health care facilities of Bunno Bedelle and llu Aba Bora Zones of Oromia regional state, South West Ethiopia. For qualitative part of this study information saturation was used to assess determinants / perceived stress level in the management of pandemic covid 19 outbreak among health care providers in llu Aba Bora and Bunno Bedelle Zones.

\section{Sampling procedures}


Simple random sampling technique was used to assess magnitude of perceived stress and associated factors among health care providers selected for the study purposes. A principle of sampling for maximum variation was followed to include health care providers in the two zones. The study participants / health care providers who met the inclusion criteria were informed about the purpose of the study and characteristics. And data was collected by self-administered and interview methods.

\section{Study variables}

\section{Dependent variables}

- Perceived stress

Independent variables

- Sex

- Age

- Ethnicity

- Religion

- Income/salary

- Marital status

- Work experience

- Professional type

- Qualification

\section{Operational definitions}

- Perceived stress: A total score of $>20$ points was considered as the cut off for experiencing perceived stress based on perceived stress scale(PSS)(11).

- Determinants of effective stress management defined as perceived stress level of professional health workers due to COVID 19 in the working site /health care facilities of the study.

- Stress management: refers to the capacity to calm down individuals who are tensioned due to pandemic corona virus outbreak.

- Health care providers: refer to all types of qualified health professionals of different disciplines. 


\section{Data collection methods}

Mixed method of quantitative and qualitative data collection procedures was used to address the specific objectives of the study. To collect data structured and semi structured questionnaire as well as tools with both open and closed ended questions was employed. The data was collected from health care providers by using standard self-administered questionnaires. A structured questionnaire adapted from WHO validated for perceived stress level was used to collect the information from the study participants. The study variables in the questionnaire were including: socio-demographic data like sex, age, professional qualification, income/salary, religion, marital status, ethnicity and work experience. Perceived stress was evaluated with ten item version of perceived stress scale (PSS) which had a wide range of applications. The scores was obtained by reversing responses $(0=4,1=3,2=2,3=1 \& 4=0)$ to the four positively stated items (items $4,5,7, \& 8$ ) and then summing across all scale items. A short four item scale can be made from questions 2, 4, 5 and 10 of the PSS 10 item scale. A five point Likert scale was employed to determine each items ( $0=$ Never, $1=$ Almost Never, $2=$ Sometimes, $3=$ Fairly Often and $4=$ Very Often $)$, yielding a totally original score ranging from 0 to 50 . A total score of $>20$ points was considered as the cut off for experiencing perceived stress due to pandemic corona virus managements among HCPs (11).

\section{Data quality assurance}

The questionnaire was designed, adopted and modified appropriately. Training was given for data collectors and supervisors. The data collectors were supervised daily and questionnaires were filled and checked on the daily basis by the supervisor and principal investigators. While problems faced solutions were given by discussing with the supervisors and the data collectors. Orientation was provided for study participants on how to complete the questionnaires. Monitoring and fallow up by supervisors and principal investigators was carried out during data collection.

\section{Data processing and analysis}

The data was organized and processed by the use of epi info and SPSS version 21. After completeness the data was checked, entered into epi info computer programs and transported to SPSS version 21 for further analysis and cleaning. Descriptive statistics were used to summarize statistical measures. Association of perceived stress related variables/problems and demographic characteristics were analyzed by using logistic regression with odds ratio and $95 \%$ confidence interval in the analysis. Multivariable logistic regression analysis was used to assess perceived stress level of effective managements of pandemic corona virus outbreak among HCPs. Odds ratios and $95 \%$ confidence intervals were analyzed. A p-value of less than 0.05 was considered as statistically significant association.

\section{Ethical consideration}


Ethical clearance was obtained from the Institutional Review Board of Mettu University.

The data collectors were clearly explained the aims of the study for study participants. Information was collected after obtaining verbal consent from each participant. The right was given to the study participants to refuse participation at any time they want and the chance to ask any thing about the study. For the purpose of anonymity participant's name was not used and all other personnel information kept confidential

\section{Results}

\section{Socio-demographic characteristics of the respondents}

The major objective of this study was to assess determinants of perceived stress in the managements of pandemic corona virus among health care providers in llu Aba Bora and Bunno Bedelle Zones. A total of 365 professional health care providers were interviewed in this study with a response rate of $100 \%$. Of these, $208(57 \%)$ were male and $157(43 \%)$ of them were female health care providers. Among the respondents $215(59 \%)$ of them was 25-30 years old. Among the respondents 202 (55\%) of them were Christian, 153 (42\%) of them Muslim. Of total participants, 274(75\%) of them were Oromo, $66(18 \%)$ of them were Amhara in ethnicity. The study revealed that $226(61.9 \%)$ of the health care providers were married and the remaining $139(38.1 \%)$ were single in marital status. The qualification of health care providers was reported that $278(76.2 \%)$ of them had first degree level. The majority of respondents 195 (53.4\%) had working experiences of in the range of $1-3$ years and the respondents of $196(53.7 \%)$ monthly income was ranging from 5000-7000 Ethiopian birr(Table 1).

Table 1: Socio-demographic characteristics of health care providers working at health facilities of Bunno Bedelle and Ilu Aba Bora Zones, 2020 


\begin{tabular}{|c|c|c|c|}
\hline Variables & Category & Frequency & $\begin{array}{l}\text { Percentage } \\
(\%)\end{array}$ \\
\hline \multirow[t]{2}{*}{ Sex } & Male & 208 & 57 \\
\hline & Female & 157 & 43 \\
\hline \multirow[t]{3}{*}{ Age } & $<25$ & 88 & 24 \\
\hline & $25-30$ & 215 & 59 \\
\hline & $>30$ & 62 & 17 \\
\hline \multirow[t]{2}{*}{ Religion } & Christian & 202 & 55 \\
\hline & Muslim & 153 & 42 \\
\hline \multirow[t]{3}{*}{ Ethnicity } & Oromo & 274 & 75 \\
\hline & Amhara & 66 & 18 \\
\hline & Others & 25 & 6.8 \\
\hline \multirow[t]{2}{*}{ Marital status } & Married & 226 & 61.9 \\
\hline & Single & 139 & 38.1 \\
\hline \multirow[t]{3}{*}{ Income } & $<5,000$ & 54 & 14.8 \\
\hline & $5,000-7,000$ & 196 & 53.7 \\
\hline & $>7,000$ & 115 & 31.5 \\
\hline \multirow[t]{2}{*}{$\begin{array}{l}\text { Profession } \\
\text { category }\end{array}$} & $\begin{array}{l}\text { BSc degree and lower in health science } \\
\text { fields }\end{array}$ & 278 & 76.2 \\
\hline & MD including specialists and masters & 87 & 23.8 \\
\hline \multirow[t]{3}{*}{ Work experience } & $<$ one year & 45 & 12.4 \\
\hline & 1-3 years & 195 & 53.4 \\
\hline & Greater than 3 years & 125 & 34.2 \\
\hline
\end{tabular}

\section{Perceived stress due to pandemic corona virus}

Perceived stress during pandemic corona virus among health care providers in llu Aba Bor and Bunno Bedelle Zones was assessed using perceived stress scale and its founf208 (57\%) of them have perceived stress during the last month of the study period(Table 2).

Table 2: Perceived Stress Level /Scale among Health Care Providers in Bunno Bedelle and Ilu Aba Bor Zones, South West, Ethiopia, 2020 


\begin{tabular}{|l|l|l|l|l|l|l|}
\hline \multicolumn{2}{|c|}{ Descriptions } & \multicolumn{3}{l}{ Perceived Stress scale/ level } \\
\hline S.N & Category & Never & $\begin{array}{l}\text { Almost } \\
\text { Never }\end{array}$ & Sometimes & $\begin{array}{l}\text { Fairly } \\
\text { often }\end{array}$ & $\begin{array}{l}\text { Very } \\
\text { often }\end{array}$ \\
\hline 1 & $\begin{array}{l}\text { Upset because of something } \\
\text { happened unexpectedly }\end{array}$ & 40 & 65 & 113 & 71 & 76 \\
\hline 2 & Bothered about Covid 19 & 25 & 88 & 115 & 69 & 78 \\
\hline 3 & $\begin{array}{l}\text { Unable to control the important } \\
\text { things }\end{array}$ & 11 & 60 & 129 & 79 & 86 \\
\hline 4 & Felt stressed & 99 & 79 & 38 & 72 & 77 \\
\hline 5 & Able to cope Covid 19 & 92 & 86 & 50 & 72 & 65 \\
\hline 6 & Could not cope with things & 80 & 78 & 62 & 84 & 61 \\
\hline 7 & $\begin{array}{l}\text { Confident about ability to handle the } \\
\text { problems }\end{array}$ & 31 & 38 & 111 & 87 & 98 \\
\hline 8 & Felt that things were going & 44 & 36 & 98 & 96 & 91 \\
\hline 9 & Felt difficulties to manage & 91 & 87 & 42 & 69 & 76 \\
\hline 10 & $\begin{array}{l}\text { Unable to overcome the tension due } \\
\text { to covid 19 }\end{array}$ & 30 & 83 & 94 & 88 & 70 \\
\hline
\end{tabular}

Perceived stress due to pandemic corona virus managements among health care workers in Buno Bedelle and Ilu Aba Bor Zones of public health facilities were analyzed using binary logistic regression. In bivariate logistic regression variables like age, sex, marital status, income, professional category, qualifications, and work experiences were found to have p-value less than 0.20 . In Multivariable binary logistic regression variables including: being married, less than one year working experience, and having BSc degree and lower educational background in health related fields had statistically significant ( p-value less than 0.05 ) with perceived stress due to pandemic corona virus.

The odds of having perceived stress due to pandemic corona virus managements among health care providers who had working experience of less than one year was 2.57 times higher as compared to health care providers who had working experience above a year with $(\mathrm{AOR}=2.57,95 \% \mathrm{Cl}: 1.83-7.32)$.

This findings also show that health care providers who had married were almost five times more likely to have perceived stress due to pandemic corona virus as compared to respondents who were single with (AOR=4.6, 95\% Cl: 3.51; 9.33).

Additionally, Participants who were BSc and lower educational background in health science fields were almost 4 times more likely to have perceived stress on pandemic corona virus managements as compared with respondents who were medical doctors including specialists and masters with (AOR=3.8, 95\%Cl: 3.81; 7.03)(Table 3). 
Table 3: Multivariable analysis of perceived stress and associated factors of pandemic corona virus outbreak among health care providers in Buno Bedelle and Ilu Aba Bor Zones, Oromia regional state, south west, Ethiopia, 2020

\begin{tabular}{|c|c|c|c|c|c|}
\hline \multirow[t]{2}{*}{ Variables } & \multirow[t]{2}{*}{ Category } & \multicolumn{4}{|c|}{ Perceived stress level } \\
\hline & & Yes & No & COR (CI) & AOR (CI) \\
\hline \multirow[t]{3}{*}{$\begin{array}{l}\text { Working } \\
\text { experience }\end{array}$} & Less than one year & 28 & 17 & $\begin{array}{l}2.96(1.43- \\
6.11)\end{array}$ & $\begin{array}{l}2.57(1.83- \\
7.32) *\end{array}$ \\
\hline & One to three years & 108 & 87 & $\begin{array}{l}0.41(0.20, \\
0.83)\end{array}$ & $\begin{array}{l}0.45(0.15, \\
1.29)\end{array}$ \\
\hline & $\begin{array}{l}\text { Greater than or equal to three } \\
\text { years }\end{array}$ & 73 & 52 & 1 & 1 \\
\hline \multirow[t]{2}{*}{$\begin{array}{l}\text { Marital } \\
\text { status }\end{array}$} & Married & 124 & 102 & $\begin{array}{l}6.82(3.71 \\
11.40)\end{array}$ & $\begin{array}{l}4.6(3.51 ; \\
9.33) *\end{array}$ \\
\hline & Single & 44 & 95 & 1 & 1 \\
\hline \multirow[t]{2}{*}{$\begin{array}{l}\text { Profession } \\
\text { category }\end{array}$} & $\begin{array}{l}\text { BSc degree and lower educational } \\
\text { background }\end{array}$ & 203 & 75 & $\begin{array}{l}4.92(3.61, \\
13.20)\end{array}$ & $\begin{array}{l}\text { 3.8(3.81; } \\
7.03) *\end{array}$ \\
\hline & $\begin{array}{l}\text { MD including specialists and } \\
\text { masters }\end{array}$ & 53 & 34 & 1 & 1 \\
\hline
\end{tabular}

*P-value is less than 0.05

\section{Discussion}

This study has tried to assess perceived stress level and associated factors of pandemic corona virus outbreak among health care providers in llu Aba Bor and Bunno Bedelle Zones. In this study magnitude of perceived stress level and socio demographic variables were described attentively by the investigators. In addition this study also tried to assess the association between perceived stress level and common independent variables.

According to this research findings magnitude of perceived stress due to pandemic corona virus among health care providers working in Ilu Aba Bora and Bunno Bedelle Zones was found to be $57 \%$. The finding of this study was in line with the study conducted in hospitals of southern nation and nationalities of Ethiopia which was $51.6 \%$ with the respondents in their life of the last month(12). Perceived stresses among the participants were bothered by things that were happening very often while some others felt well fairly often. On the other hand, the majority of respondents were able to complete the important events in their life properly while others couldn't cope with all the things happening.

On the other hand, the study done in china Wuhan by Dai Y, et al was lower as compared to this study $39.1 \%$. The possible evidences for the difference among the findings might be due to sampling size, 
sampling technique and different tool /instruments what were used(13). The difference in study population and study area might also bring the variety of the study findings.

The probability of perceiving stress due to pandemic corona virus among health care providers having less than one year working experience is 2.57 times higher as compared to health care providers who had working experience greater than one year with $95 \%$ level of confidence $\mathrm{AOR}=2.57, \mathrm{Cl}: 1.83 ; 7.32)$. This association might occur due to lack adequate information about COVID 19 outbreak or might be due to experience that makes them adopt and tolerate stressful situations.

This study shows the chance of having perceived stress due to pandemic corona virus among married health care providers is 4.6 times higher as compared to health care providers who were single with ( $A O R=4.6, \mathrm{Cl}: 3.51 ; 9.33)$. This might be evidenced by those married health professionals worry about catching and bringing Covid 19 virus to their family(12).

This study findings shown that the majority $278(76.2 \%)$ of respondents/ health care providers had BSc and lower educational background in health science fields. This study analysis reveals that perceived stress due to pandemic corona virus is 3.8 times common among health care providers who had BSc and lower educational background in health science fields as compared to those who had high health professionals trainings (MD including specialists and masters (AOR=3.8, Cl: $3.81 ; 7.03$ ). This finding is supported by the study conducted in China on perceived stress of pandemic corona virus among health care workers(11). It could be evidenced by those who have lower level of educational background is highly involved directly in helping clients with pandemic corona virus and they are at high risks(14).

Generally according to this study results; having less than one year working experiences, being married and BSc and lower educational background among health care providers showed statistically significant associations.

The limitation of the current study is that it cannot show temporal relationship between level of perceived stress and significant associated factors since a cross-sectional study design was utilized in this study.

\section{List Of Abbreviations}


Ebr Ethiopian birr

EMOH Ethiopian Ministry of Health

IDI In depth Interview

HCP Health Care Providers

LMICs Low and Middle Income Countries

MD Medical Doctors

MHPs Mental health professionals

MKSH Mettu Karl Specialized Hospital

PPE Personal protective equipment

PSS Perceived stress scale

SARS Severe Acute Respiratory Syndrome

SPSS Statistical Package for Social Sciences

USA United States of America

WHO World Health organization

\section{Declarations}

\section{Funding}

A fund for this study was provided by Mettu University.

\section{Disclosure}

Since this study was done for educational purposes, the funder has no role in the publication and use of this study.

\section{Declaration of interest}

The authors declare that they have no competing interests.

\section{Data Availability}

The data used to support the findings of this study are available from the corresponding author upon request.

\section{Acknowledgments}


We would like to thank Mettu University for encouraging and giving us the chance to participate in such research project preparation as well as for funding our project. We also like to express our profound gratitude to college of Health Sciences Research committee for their constructive comments and guidance.

\section{Authors' Contributions}

YA participated in the development of the proposal, analysis, interpretation, writing of the manuscript, and supervision of the group. AK participated in the development of the proposal, analysis, writing of the manuscript, and supervision of the data collection process. EG participated in the development of the proposal; and analysis and interpretation of the manuscript. GT participated in the development of the proposal, data collection process and analysis. LB participated in the development of the proposal, analysis, and reviewing and writing of the manuscript.

\section{References}

1. T. L. Handbook of COVID-19 Prevention and Treatment Compiled According to Clinical Experience, the First Affiliated Hospital, Zhejiang University School of Medicine. 2020;68.

2. Organization WH. Health workers exposure risk assessment and management in the context of COVID-19 virus Interim guidance 4 March 2020.

3. WHO C, World Vision International \& UNICEF. Psychological first aid during Ebola virus disease outbreak.WHO: Geneva 2017.

4. (ILO) WatILO. Occupational safety and health in public health emergencies: A manual for protecting health workers and responders. WHO \& ILO: Geneva. 2019.

5. R. Y. Risk and resilience in posttraumatic stress disorder. J Clinical Psychiatry. 2004;65(Suppl 1):2936.

6. Moynihan JA. "MechaSnisms of Stress-Induced Modulation of Immunity." Brain, Behavior, and Immunity. 2003;17(Suppl 1),:S11-S6.

7. Glaser R, and Kiecolt-Glaser, J. K. “Stress-Induced Immune Dysfunction: Implications for Health.” Nature Reviews. Immunology. 2005;5:243-51.

8. Action TAfCPiH. Guidance note: Protection of children during infectious disease outbreaks 2020.

9. (mhGAP-HIG WUNHCfRmHIG. Clinical Management of Mental, Neurological and Substance Use Conditions in Humanitarian Emergencies. WHO: Geneva, . 2018.

10. action TAfCpih. Minimum Standards for Child Protection in Humanitarian Action. 2019.

11. Alavi Arjomand N KNZ, Hosseini MA, Reza Soltani P. Study of the impact of stress management on work. 2020.

12. Chekole YA. Prevalence and risk factors of perceived stress on COVID-19 among health care providers in Dilla Town. Health institutions, Southern Ethiopia: A cross sectional study. 2020. 
13. Wang C PR, Wan X, Tan Y, Xu L, Ho CS, et al. Immediate psychological responses and associated factors during the initial stage of the 2019 coronavirus disease (COVID-19) epidemic among the general population in China. International Journal of Environmental Research and Public Health. . 2020( 17 (5):1729.).

14. Ahmadi T SN, Medizade Tazangi R, Taheri M. . Students' life quality prediction based on life skills. Procedia - Social and Behavioral Sciences. 2011;30:1980-2. 